\title{
AVALIAÇÃO DA DESORDEM NUTRICIONAL DE PLANTAS DE AMENDOIM CULTIVADAS EM SOLUÇÃO NUTRITIVA SUPRIMIDAS DE MACRONUTRIENTES
}

\section{EVALUATION OF NUTRITIONAL DISORDER OF PEANUT PLANTS CULTIVATED IN NUTRIENT SOLUTION SUPRESSED OF MACRONUTRIENTS}

\author{
Marcus André Ribeiro CORREIA ${ }^{1}$ \\ Renato de Mello PRADO ${ }^{2}$ \\ Thiago Batista Firmato ALMEIDA ${ }^{3}$ \\ Aline Peregrina PUGA ${ }^{4}$ \\ José Carlos BARBOSA ${ }^{5}$
}

\section{RESUMO}

Com o objetivo de avaliar o efeito da omissão de macronutrientes no crescimento e no estado nutricional do amendoim (Arachis hypogaea L.), bem como descrever sintomas visuais de deficiência nutricional, foi desenvolvido um experimento em solução nutritiva na FCAV/UNESP. O delineamento experimental foi o inteiramente casualizado, com sete tratamentos, que corresponderam à solução completa e à omissão individual de $\mathrm{N}, \mathrm{P}, \mathrm{K}, \mathrm{Ca}, \mathrm{Mg}$ e $\mathrm{S}$, com três repetições. As plantas de amendoim cv. Runner IAC 886 foram cultivadas em solução nutritiva de Hoagland \& Arnon em vasos contendo 5 $\mathrm{dm}^{3}$. Foram avaliados a altura das plantas, o diâmetro do caule, o número de folhas, o índice SPAD, a massa seca da parte aérea, das raízes e planta inteira, os teores e o acúmulo dos macronutrientes na parte aérea e raízes e a descrição das desordens nutricionais. A omissão de $\mathrm{K}, \mathrm{Ca}, \mathrm{N}, \mathrm{P}$ e Mg foram as que mais limitaram o crescimento vegetativo do amendoim, reduzindo consideravelmente a altura, o diâmetro do caule, o número de folhas, assim como a produção da massa seca do amendoim. Foram observados sintomas de deficiência nutricional de cada elemento. Os teores de nutrientes observados nas plantas de amendoim do tratamento completo e da omissão, na parte aérea, foram, respectivamente: $\mathrm{N}=19,0-12,2 ; \mathrm{P}=4,7$ $-1,1 ; \mathrm{K}=27,9-4,7 ; \mathrm{Ca}=10,4-1,6 ; \mathrm{Mg}=6,2-0,96 ; \mathrm{S}=1,2-0,7 \mathrm{~g} \mathrm{~kg}^{-1}$.

Palavras-chave: Arachis hypogaea; deficiência nutricional; nutrição mineral; hidroponia.

The experiment was carried out under greenhouse conditions to evaluate the effects of macronutrient omission, nutritional status, and development on peanut (Arachis hypogaea L.), as well to describe nutritional deficiency symptoms. The experiment was arranged in a completely randomized design with three replications and seven treatments, corresponding to a complete nutritive solution and individual omission of $\mathrm{N}, \mathrm{P}, \mathrm{K}, \mathrm{Ca}, \mathrm{Mg}$, and $\mathrm{S}$. The peanut plants cultivar Runner IAC 886 were grown in a Hoagland \& Arnon nutrient solution in $5 \mathrm{dm}^{3}$ pots. Plant height, stem diameter, leaves number, SPAD index, dry mass of aerial part, root, and hole plant, as well the nutritional disorder description were evaluated. The omission of $\mathrm{K}, \mathrm{Ca}, \mathrm{N}$, $\mathrm{P}$ and $\mathrm{Mg}$ showed the higher growth limiter to the peanut growth, reducing considerably the plant height, stem diameter, number of leaves and also reducing the peanut dry mass production. Nutritional deficiency symptoms of each nutrient were observed. Macronutrient levels observed in peanut plants were, respectively to the control and to the treatment with nutrient omission were: $\mathrm{N}=19.0-12.2, \mathrm{P}=4.07-1.1, \mathrm{~K}=27.9-4.7, \mathrm{Ca}=10.4-1.6, \mathrm{Mg}=6.2-0.96, \mathrm{~S}=1.2-0.7 \mathrm{~g} \mathrm{~kg}^{-1}$.

Key-words: Arachis hypogaea; nutritional deficiency; mineral nutrition; hydroponics.

\footnotetext{
${ }^{1}$ Pós-Graduando em Agronomia (Produção Vegetal), Depto. de Solos e Adubos, Faculdade de Ciências Agrárias e Veterinárias, UNESP. Email: marcus.agro@hotmail.com

${ }_{2}^{2}$ Prof. Dr., Depto. de Solos e Adubos, Faculdade de Ciências Agrárias e Veterinárias, UNESP. E-mail: rmprado@fcav.unesp.br

${ }^{3}$ Pós-Graduandos em Agronomia (Ciência do Solo), Depto. de Solos e Adubos, Faculdade de Ciências Agrárias e Veterinárias, UNESP. Email: thibalmeida@gmail.com

${ }^{4}$ Doutoranda em Agricultura Tropical e Subtropical, Instituto Agronômico de Campinas (IAC). E-mail: linepuga@gmail.com

${ }^{5}$ Prof. Dr., Depto. de Ciências Exatas, Faculdade de Ciências Agrárias e Veterinárias, UNESP. E-mail: jcbarbosa@fcav.unesp.br
} 
CORREIA, M.A.R. et al. Avaliação da desordem nutricional...

\section{INTRODUÇÃO}

O amendoim (Arachis hypogaea L.) pertence à família Leguminosae e é uma das principais oleaginosas produzidas no mundo. Suas sementes, compostas por óleo, proteína, vitamina (E e do complexo B) e minerais, possuem alto valor nutritivo e sabor agradável. Os grãos podem ser consumidos in natura ou processados industrialmente para fabrica de doces e salgados ou no segmento oleoquímico Freire et al. (2005).

A produção da cultura do amendoim, em sua quase totalidade, advém de áreas de reforma de canaviais (Crusciol \& Soratto, 2007). Esta prática, ou seja, o cultivo de espécies anuais em áreas de reforma de cana-de-açúcar está possibilitando o aumento do cultivo das culturas alimentícias, (Lombardi, 1985).

Apesar da importância econômica da cultura do amendoim são necessários avanços nos estudos sobre a nutrição da planta devido à baixa fertilidade dos solos tropicais. Neste sentido, estudos indicam que $\mathrm{o}$ fornecimento de macronutrientes para a cultura do amendoim cultivado em solo promoveu aumento próximo de $85 \%$ na matéria seca dos frutos e $53 \%$ na matéria seca da planta Coelho \& Tella (1967).

$\mathrm{Na}$ literatura, são incipientes os trabalhos completos sobre nutrição dos macronutrientes para a cultura do amendoim, especialmente sobre os efeitos de sua omissão no crescimento e na desordem nutricional. E ainda a informação disponível sobre o efeito de deficiências minerais em amendoim (FEITOSA et al., 1993) foi obtida na década de 90 , com variedade não utilizada em nossas condições atuais e, portanto, existe a necessidade de pesquisas com essa cultura devido ao surgimento de novos genótipos.

Neste contexto, o trabalho visou a avaliar o efeito da omissão de macronutrientes no crescimento e no estado nutricional do amendoim, bem como descrever sintomas visuais de deficiência nutricional, cultivado em solução nutritiva, em experimento desenvolvido na FCAV/UNESP.

\section{MATERIAL E MÉTODOS}

O experimento foi realizado na Faculdade de Ciências Agrárias e Veterinárias da UNESP, Câmpus de Jaboticabal, Estado de São Paulo, cujas coordenadas geográficas são: $21^{\circ} 15^{\prime} 22^{\prime \prime}$ sul, $48^{\circ} 18^{\prime} 58^{\prime \prime}$ oeste e altitude de $575 \mathrm{~m}$, utilizando a cultura do amendoim, cv. Runner IAC 886, em vasos contendo $5 \mathrm{dm}^{3}$ de solução nutritiva.

Os tratamentos foram constituídos por: 1completo (N, P, K, Ca, Mg, S , B, Cl, Cu, Fe, Mn, Mo e Zn); 2- omissão de nitrogênio (-N); 3- omissão de fósforo (-P); 4- omissão de potássio (-K); 5omissão de cálcio (-Ca); 6- omissão de magnésio ($\mathrm{Mg}$ ); 7- omissão de enxofre (-S), dispostos em um delineamento inteiramente casualizado, com três repetições. Realizou-se durante a condução do experimento o rodízio dos vasos a cada semana, para proporcionar as mesmas condições de temperatura, umidade e luminosidade para os tratamentos.

A semeadura do amendoim foi realizada em bandeja de 200 células em substrato comercial

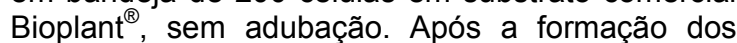
primeiros ramos laterais, a dez dias da emergência (DAE), duas plântulas foram transplantadas para vasos contendo $5 \mathrm{dm}^{-3}$ de solução nutritiva de Hoagland \& Arnon (1950), diluída a $25 \%$, da concentração usual, mantidos durante a primeira semana de cultivo, solução diluída a $50 \%$ para a segunda semana de cultivo e após esse período até o final do experimento (8 semanas de cultivo), utilizou-se a presente solução nutritiva sem a diluição. As soluções nutritivas foram substituídas a cada quinze dias, para reposição dos nutrientes à solução, por meio de soluções estoque preparadas de acordo com os tratamentos.

Ressalta-se que, para o manejo das soluções nutritivas ao longo do período de estudo, o pH foi monitorado diariamente, ajustando-se a $5,5 \pm$ 0,5 , usando-se solução $\mathrm{NaOH}$ ou $\mathrm{HCl} 0,1 \mathrm{~mol} \mathrm{dm}^{-3}$. Para a reposição da água evapotranspirada, foi utilizada água desionizada, sendo a solução nutritiva oxigenada, a partir do uso do compressor de ar controlado por um temporizador "timer" programado durante o dia (de $6 \mathrm{~h}$ às $18 \mathrm{~h}$ ) para permanecer ligado, com distribuição do ar por canos de ferro na linha principal com saídas para encaixe de mangueira de silicone conectadas na linha e em cada unidade experimental.

As plantas foram colhidas após oito semanas do transplantio (fase de frutificação) e nessa ocasião, determinou-se a altura das plantas, medida da base da espuma fenólica, rente ao vaso, até a parte mais alta da planta, o diâmetro do caule determinado com o uso de um paquímetro digital (Starrett $727-2001^{\circledR}$ ) na base da espuma fenólica, rente ao vaso, e o número total de folhas na planta. Salienta-se, ainda, que foi realizada a medida indireta do teor de clorofila a partir da leitura SPAD, em dez folhas por unidade experimental, com auxílio do aparelho CCM-200.

O material vegetal colhido foi lavado com água desionizada e separado em parte aérea e raízes, e colocado para secar em estufa de ventilação forçada a $65^{\circ} \mathrm{C}$ até massa constante, e determinou-se a massa da matéria seca. $\mathrm{E}$, em seguida, o material vegetal foi moído (moinho tipo Willey), para a análise química, determinando-se os teores dos macronutrientes na matéria seca da parte aérea e das raízes, conforme método descrito por Bataglia et al. (1983). Posteriormente, realizou-se o cálculo do acúmulo de nutrientes na parte aérea, raiz e, posteriormente, na planta inteira. Durante todo o período experimental, fizeram-se descrições da sintomatologia visual de deficiência nutricional nas plantas, inerente a cada tratamento.

Para os resultados obtidos, realizou-se a análise de variância e, para comparação das médias, o teste de Tukey $(p<0,05)$, utilizando o software AGROESTAT. Optou-se em indicar apenas a diferença significativa apontada pelo teste de compara- 
CORREIA, M.A.R. et al. Avaliação da desordem nutricional...

ção de médias, em relação ao tratamento com a omissão do nutriente e o completo, objeto principal do estudo.

\section{RESULTADOS E DISCUSSÃO Nitrogênio}

As variáveis indicativas de crescimento das plantas de amendoim foram afetadas com a omissão do nitrogênio de forma significativa, ocorrendo redução na altura das plantas, no número de folhas e no diâmetro do caule, e na massa seca das plantas, em relação ao tratamento completo (Tabela 1).

TABELA 1. Altura, diâmetro do caule, número de folhas índice SPAD e massa seca das plantas de amendoim, em função da omissão de macronutrientes na solução nutritiva.

\begin{tabular}{|c|c|c|c|c|c|c|c|}
\hline Tratamentos & Altura & Diâmetro & $\mathrm{N}^{\circ} \mathrm{de}$ & SPAD & \multicolumn{3}{|c|}{ Matéria seca } \\
\hline & & & & & Parte aérea & Raízes & $\begin{array}{l}\text { Planta } \\
\text { inteira }\end{array}$ \\
\hline & $\mathrm{cm}$ & $\mathrm{mm}$ & & & \multicolumn{3}{|c|}{ - g planta ${ }^{-1}$} \\
\hline Completo & 36,43 & 5,70 & 100 & 53,00 & 14,99 & 2,06 & 17,06 \\
\hline$-N$ & $26,16^{\star}$ & $4,66^{*}$ & $40^{*}$ & $14,53^{*}$ & $3,28^{*}$ & $1,15^{*}$ & $4,43^{*}$ \\
\hline$-P$ & $28,33^{*}$ & $4,90^{*}$ & $75^{*}$ & $24,38^{*}$ & $10,34^{*}$ & 2,50 & $12,85^{*}$ \\
\hline$-K$ & $19,00^{*}$ & $3,73^{*}$ & $42^{*}$ & $14,51^{*}$ & $2,31^{*}$ & $0,46^{*}$ & $2,78^{*}$ \\
\hline - $\mathrm{Ca}$ & $20,20^{*}$ & $4,63^{*}$ & $47^{*}$ & $19,74^{*}$ & $3,34^{*}$ & $0,64^{*}$ & $3,99^{*}$ \\
\hline$-M g$ & $28,66^{*}$ & $4,90^{*}$ & $76^{*}$ & $22,16^{*}$ & $10,88^{*}$ & 1,95 & $12,84^{*}$ \\
\hline$-S$ & $29,00^{*}$ & $4,86^{*}$ & 95 & $24,14^{*}$ & 14,06 & 2,02 & 16,09 \\
\hline$F$ & $32,99^{* *}$ & $27,80^{* *}$ & $43,26^{* *}$ & $44,49^{* *}$ & $46,98^{* *}$ & $22,27^{* *}$ & $57,41^{* *}$ \\
\hline DMS & 4,95 & 0,53 & 18,33 & 9,52 & 3,79 & 0,80 & 3,87 \\
\hline C.V.\% & 6,6 & 3,9 & 9,6 & 13,8 & 16,0 & 18,6 & 13,9 \\
\hline
\end{tabular}

*Diferença significativa pelo teste de Tukey $(p<0,05)$, na coluna, em relação ao tratamento com a solução nutritiva com a omissão do nutriente e com a solução nutritiva completa.

** - Significativo a $1 \%$ de probabilidade pelo teste F; DMS- Diferença Mínima Significativa; C.V.- Coeficiente de Variação.

A diminuição das variáveis de crescimento e da massa seca das plantas de amendoim, em decorrência da deficiência do nitrogênio, é bastante relatada na literatura, devido ao nitrogênio ser parte constituinte de todos os aminoácidos, proteínas e ácidos nucléicos, participando direta ou indiretamente de vários processos bioquímicos, sendo que sua carência promoverá a redução na síntese de clorofila e aminoácidos essenciais, e também da energia necessária à produção de carboidratos e esqueletos carbônicos, refletindo diretamente no desenvolvimento das plantas e no rendimento da cultura Malavolta et al. (1997).

Além disso, no tratamento com a omissão do nitrogênio, houve redução de $72,5 \%$ do índice SPAD, devido a este nutriente estar relacionado com a formação da clorofila, pigmento no tecido dos vegetais que confere a cor verde. Segundo Caires \& Rosolem (1999), o aumento na produção de amendoim tem-se relacionado com o aumento da concentração de clorofila nas folhas devido à maior absorção de nitrogênio.
O tratamento completo apresentou teor de $\mathrm{N}$ na parte aérea e na raiz de $19,0 \mathrm{~g} \mathrm{~kg}^{-1}$ e de $29,6 \mathrm{~g}$ $\mathrm{kg}^{-1}$, respectivamente, enquanto no tratamento com omissão deste nutriente, o teor de $\mathrm{N}$ na parte aérea e raiz foi de 12,2 e $20,3 \mathrm{~g} \mathrm{~kg}^{-1}$, respectivamente (Tabela 2).

Segundo Ambrosano et al. (1997), a faixa de teor considerada adequada na massa seca das folhas de amendoim é de $30-45 \mathrm{~g} \mathrm{~kg}^{-1}$ de $\mathrm{N}$ coletadas no florescimento, no tufo apical do ramo principal. As diferenças no teor de $\mathrm{N}$ entre o tratamento completo e o da literatura devem-se ao material vegetal distinto, pois, do presente trabalho, consideraram--se todas as folhas da parte aérea, e da literatura apenas as folhas mais jovens (tufo apical), o que confere maior teor de $\mathrm{N}$ dada sua alta mobilidade na planta. Apesar de o teor de $\mathrm{N}$ do tratamento completo estar abaixo da faixa de teor adequado, segundo Ambrosano et al. (1997), não foi observado sintomatologia de deficiência de nitrogênio, ao contrário do tratamento com omissão de $\mathrm{N}$, que apresentou sintomatologia de deficiência e redução no desenvolvimento das plantas (Tabela 1). 
CORREIA, M.A.R. et al. Avaliação da desordem nutricional...

TABELA 2. Teores de nutrientes na parte aérea e raízes das plantas de amendoim, em função da omissão de macronutrientes na solução nutritiva.

\begin{tabular}{|c|c|c|c|c|c|c|}
\hline Tratamentos & $\mathrm{N}$ & $\mathrm{P}$ & $\mathrm{K}$ & $\mathrm{Ca}$ & $\mathrm{Mg}$ & $S$ \\
\hline & \multicolumn{6}{|c|}{ Parte aérea } \\
\hline & \multicolumn{6}{|c|}{ g kg ${ }^{-1}$ - } \\
\hline Completo & 19,0 & 4,7 & 27,9 & 10,4 & 6,2 & 1,2 \\
\hline$-N$ & $12,2^{*}$ & $9,2^{*}$ & 24,5 & $12,9^{*}$ & 6,5 & $2,2^{*}$ \\
\hline$-P$ & 21,2 & $1,1^{*}$ & 21,7 & 10,8 & 5,2 & 1,0 \\
\hline$-K$ & $35,5^{*}$ & $9,8^{*}$ & $4,7^{*}$ & $12,4^{*}$ & $10,6^{*}$ & $2,1^{*}$ \\
\hline - Ca & $36,7^{\star}$ & $6,5^{*}$ & 27,9 & $1,6^{*}$ & $10,4^{\star}$ & $1,9^{*}$ \\
\hline$-\mathrm{Mg}$ & $24,3^{*}$ & $7,0^{*}$ & 29,8 & 11,1 & $0,96^{*}$ & 1,1 \\
\hline$-S$ & 18,7 & 4,5 & 26,5 & 8,9 & 5,4 & $0,7^{*}$ \\
\hline $\mathrm{F}$ & 135,25 & 150,82 & $30,88 '$ & 137,00 & $112,71^{\prime \prime}$ & 157,40 \\
\hline DMS & 3,76 & 1,18 & 7,46 & 1,57 & 1,51 & 0,22 \\
\hline \multirow[t]{2}{*}{ C.V.(\%) } & 5,6 & 6,9 & 11,4 & 5,7 & 8,3 & 5,4 \\
\hline & \multicolumn{6}{|c|}{ Raízes } \\
\hline Completo & 29,6 & 11,8 & 23,0 & 9,3 & 4,6 & 3,7 \\
\hline$-N$ & $20,3^{*}$ & $9,2^{*}$ & 24,3 & $4,0^{*}$ & $3,5^{*}$ & 4,3 \\
\hline$-P$ & 27,4 & $1,2^{*}$ & 23,8 & $1,1^{*}$ & $1,9^{*}$ & 4,0 \\
\hline$-K$ & 31,6 & 10,2 & $2,8^{*}$ & $3,1^{*}$ & $6,6^{*}$ & 2,8 \\
\hline - $\mathrm{Ca}$ & 36,6 & $6,3^{*}$ & $12,0^{*}$ & $3,6^{*}$ & 3,8 & 4,4 \\
\hline$-M g$ & 31,2 & 11,2 & $30,2^{*}$ & $14,0^{*}$ & $0,7^{*}$ & 3,3 \\
\hline$-S$ & 30,0 & 10,6 & 22,0 & $11,8^{*}$ & 3,7 & 3,2 \\
\hline $\mathrm{F}$ & $11,63^{m \prime}$ & $77,66 "$ & $46,07^{\prime \prime \prime}$ & $414,24 "$ & $62,66 "$ & $6,75^{\prime \prime \prime}$ \\
\hline DMS & 7,03 & 2,04 & 6,55 & 1,17 & 1,14 & 0,94 \\
\hline C.V.(\%) & 8,5 & 8,4 & 11,9 & 6,2 & 11,4 & 9,5 \\
\hline
\end{tabular}

*Diferença significativa pelo teste de Tukey $(p<0,05)$, na coluna, em relação ao tratamento com a solução nutritiva com a omissão do nutriente e com a solução nutritiva completa.

** - Significativo a $1 \%$ de probabilidade pelo teste F; DMS- Diferença Mínima Significativa; C.V.- Coeficiente de Variação.

Rodrigues Filho et al. (1988) não observaram diferença no teor de $\mathrm{N}$ entre o tratamento completo e o tratamento com omissão de N. Os autores justificam que este fato ocorreu, provavelmente, devido a uma aplicação de pequena quantidade de nitrogênio necessária para o arranque inicial das plantas adicionadas ao tratamento com a omissão do elemento.

A omissão do nitrogênio na solução nutritiva afetou o acúmulo de $\mathrm{N}$ na parte aérea, raiz e planta inteira, sendo os teores encontrados na planta inteira, no tratamento completo e na omissão, respectivamente, de 348,0 e $64,5 \mathrm{mg}$ planta $^{-1}$ (Tabela 3).
Em decorrência da omissão de nitrogênio ter afetado sua absorção pela planta, diminuindo o crescimento e a produção de matéria seca, ela induziu o surgimento de sintomas visuais característicos. As plantas com omissão de $\mathrm{N}$ apresentaram sintomas inicias de amarelecimento das folhas mais velhas, seguidos de um leve amarelecimento da planta em geral, concordando com a sintomatologia descrita por Rodrigues Filho et al. (1988). Apresentaram ainda folhas de tamanho reduzido e menor desenvolvimento da planta por inteiro. Conforme Malavolta et al. (1997), este sintoma está associado com a menor produção de clorofila, ocasionando modificação nos cloroplastos. 
CORREIA, M.A.R. et al. Avaliação da desordem nutricional...

TABELA 3. Nutrientes acumulados na parte aérea, raízes e na planta inteira do amendoim, em função da omissão de macronutrientes na solução nutritiva.

\begin{tabular}{|c|c|c|c|c|c|c|}
\hline Tratamentos & $\mathrm{N}$ & $P$ & $\mathrm{~K}$ & $\mathrm{Ca}$ & $\mathrm{Mg}$ & $\mathrm{S}$ \\
\hline & \multicolumn{6}{|c|}{ Parte aérea } \\
\hline & & & $-\mathrm{mg} \mathrm{por}$ & ta -- & & \\
\hline Completo & 286,8 & $\begin{array}{l}70,8 \\
\end{array}$ & 419,0 & 157,4 & 93,7 & 18,9 \\
\hline$-N$ & $40,8^{*}$ & $30,3^{*}$ & $79,9^{*}$ & $42,4^{*}$ & $21,1^{*}$ & $7,1^{*}$ \\
\hline$-P$ & 219,1 & $11,7^{*}$ & $230,8^{*}$ & 111,8 & $54,0^{*}$ & $11,1^{*}$ \\
\hline$-\mathrm{K}$ & $82,3^{*}$ & $22,9^{*}$ & $10,9^{*}$ & $28,7^{*}$ & $24,7^{*}$ & $4,9^{*}$ \\
\hline - $\mathrm{Ca}$ & $123,1^{*}$ & $22,0^{*}$ & $93,1^{*}$ & $5,5^{*}$ & $35,0^{*}$ & $6,5^{*}$ \\
\hline$-M g$ & 268,2 & 77,4 & 326,1 & 121,9 & $10,8^{*}$ & $12,0^{*}$ \\
\hline$-S$ & 262,6 & 62,8 & 373,0 & 125,6 & 76,4 & $10,2^{*}$ \\
\hline $\mathrm{F}$ & 16,40 & 18,12 & $25,87^{\prime \prime}$ & 31,50 & 37,14 & 16,39 \\
\hline$\overline{\mathrm{DMS}}$ & 118,89 & 30,50 & 152,02 & 50,02 & 24,40 & 5,58 \\
\hline \multirow[t]{2}{*}{ C.V.(\%) } & 23,2 & 25,6 & 24,8 & 21,1 & 19,3 & 19,7 \\
\hline & \multicolumn{6}{|c|}{ Raízes } \\
\hline Completo & 61,2 & 24,4 & 47,5 & 19,3 & 9,6 & 7,7 \\
\hline$-N$ & $23,6^{*}$ & $10,7^{*}$ & $27,7^{*}$ & $4,6^{*}$ & $4,0^{*}$ & 4,9 \\
\hline$-P$ & 67,0 & $3,1^{*}$ & 58,9 & $2,8^{*}$ & $4,6^{*}$ & 10,0 \\
\hline$-K$ & $14,9^{*}$ & $4,8^{*}$ & $1,3^{*}$ & $1,4^{*}$ & $3,1^{*}$ & $1,3^{*}$ \\
\hline - $\mathrm{Ca}$ & $23,8^{*}$ & $4,1^{*}$ & $7,8^{*}$ & $2,3^{*}$ & $2,4^{*}$ & $2,2^{*}$ \\
\hline$-M g$ & 61,0 & 21,9 & 59,0 & $27,3^{*}$ & $1,5^{*}$ & 6,4 \\
\hline$-S$ & 60,7 & 21,6 & 44,6 & 24,0 & 7,5 & 6,4 \\
\hline $\mathrm{F}$ & 28,26 & 57,95 & $42,33^{\prime \prime}$ & $102,85^{\prime \prime}$ & 42,97 & 21,00 \\
\hline DMS & 20,51 & 5,98 & 17,47 & $\overline{5,41}$ & 2,13 & 3,20 \\
\hline \multirow[t]{2}{*}{ 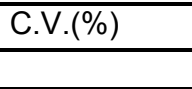 } & 16,4 & 16,5 & 17,7 & 16,5 & 16,2 & 20,5 \\
\hline & \multicolumn{6}{|c|}{ Planta inteira } \\
\hline Completo & 348,0 & 95,3 & 466,6 & 167,1 & 103,3 & 26,3 \\
\hline$-N$ & $64,5^{*}$ & $41,4^{*}$ & $107,6^{*}$ & $41,1^{*}$ & $25,3^{*}$ & $12,3^{*}$ \\
\hline$-P$ & 286,2 & $15,6^{*}$ & $289,7^{*}$ & $114,7^{*}$ & $60,5^{*}$ & 21,1 \\
\hline$-K$ & $97,2^{*}$ & $27,8^{*}$ & $12,2^{*}$ & $30,2^{*}$ & $27,7^{*}$ & $6,5^{*}$ \\
\hline - Ca & $147,0^{*}$ & $26,1^{*}$ & $101,0^{*}$ & $7,8^{*}$ & $37,6^{*}$ & $9,1^{*}$ \\
\hline$-M g$ & 329,2 & 97,2 & 385,2 & $136,9^{*}$ & $12,3^{*}$ & 19,6 \\
\hline$-S$ & 323,4 & 84,4 & 417,6 & 149,6 & 84,4 & $16,9^{*}$ \\
\hline $\mathrm{F}$ & $22,22 "$ & 33,28 & 34,94 & $134,41^{\prime \prime \prime}$ & 22,09 & 16,90 \\
\hline DMS & 123,75 & 29,75 & 146,80 & 26,88 & 34,62 & 8,27 \\
\hline C.V.\% & 19,4 & 19,2 & 20,7 & 10,4 & 24,7 & 18,5 \\
\hline
\end{tabular}

*Diferença significativa pelo teste de Tukey $(p<0,05)$, na coluna, em relação ao tratamento com a solução nutritiva com a omissão do nutriente e com a solução nutritiva completa.

"*- Significativo a 1 \% de probabilidade pelo teste F; DMS- Diferença Mínima Significativa; C.V.- Coeficiente de Variação.

\section{Fósforo}

Notou-se que em condições de ausência de fósforo as plantas apresentaram diminuição no número de folhas, altura da planta e diâmetro do caule, refletindo na produção da massa seca da parte aérea das plantas de amendoim (Tabela 1). Entretanto, a massa seca da raiz, no tratamento completo, foi semelhante ao tratamento com omissão de fósforo (Tabela 1).

Rodrigues Filho et al., (1988) observaram que, as menores reduções da massa da matéria seca ocorreu com a omissão de fósforo. Esse fato deve-se, possivelmente, à estratégia da planta em condições adversas de disponibilidade de fósforo induzir o aumento do volume das raízes, observado no experimento, a fim de aumentar a capacidade de aquisição do elemento, proporcionando, assim, maior proximidade entre a superfície absortiva da raiz e o nutriente.

A ausência da aplicação de fósforo na solução nutritiva provocou redução significativa do seu teor na parte aérea e raiz, em relação ao tratamento completo e com a omissão de $P$, sendo os valores de 4,7 e 1,1 $\mathrm{g} \mathrm{kg}^{-1}$ na parte aérea, e 11,8 e 
CORREIA, M.A.R. et al. Avaliação da desordem nutricional...

$1,2 \mathrm{~g} \mathrm{~kg}^{-1}$ nas raízes, respectivamente (Tabela 2). O tratamento com solução completa apresentou teor de $P\left(4,7 \mathrm{~g} \mathrm{~kg}^{-1}\right)$ dentro da faixa considerada adequada (2 a $5 \mathrm{~g} \mathrm{~kg}^{-1}$ ) por Ambrosano et al. (1997), sendo que o tratamento com a omissão do nutriente apresentou teor de $P\left(1,1 \mathrm{~g} \mathrm{~kg}^{-1}\right)$ abaixo dessa faixa adequada (Tabela 2). Houve incremento significativo no acúmulo de $\mathrm{P}$ no tratamento completo em relação ao tratamento com omissão do nutriente, na parte aérea, raízes e planta inteira. Os valores acumulados no tratamento com o nutriente, em relação ao tratamento com a omissão de $P$, nas diferentes partes analisadas, foram de 70,8 e 11,7; 24,4 e 3,1; 95,3 e 15,6 mg de P por planta, respectivamente, (Tabela 3). Feitosa et al. (1993) observaram o acúmulo total de fósforo em quatro variedades de amendoim e obtiveram valores variando de 10,0 a $14,5 \mathrm{~kg} \mathrm{ha}^{-1}$ de $\mathrm{P}$ e concluíram que a época de maior absorção pela parte aérea coincidiu com aquela de maior produção da massa de matéria seca da parte aérea.

A omissão de $P$ nas plantas proporcionou aparecimento de sintomas visuais, como diminuição pouco acentuada no crescimento e desenvolvimento das plantas. Folhas mais velha apresentaram coloração verde mais escura, seguindo-se de pigmentos roxos na nervura central. Esse sintoma de arroxeamento seria decorrente do acúmulo de fotoassimilados nos tecidos, o que favorece a síntese de antocianina, pigmento que confere essa coloração (Mengel \& Kirkby, 1987). Portanto, as plantas deficientes em fósforo tiveram o crescimento retardado devido ao seu papel na nutrição de plantas, ligado à função estrutural, no processo de transferência e armazenamento de energia, afetando vários processos metabólicos, como a síntese de proteínas e ácido nucléico (Prado, 2008).

\section{Potássio}

Os parâmetros vegetativos indicativos de crescimento foram afetados significativamente pela omissão de potássio. O tratamento com omissão de potássio apresentou redução respectivamente, de $48 ; 34 ; 58 ; 72 ; 84 ; 77$ e $83 \%$ para a altura das plantas, diâmetro do caule, número de folhas, índice SPAD, massa seca da parte aérea, raízes e planta inteira do amendoim (Tabela 1).

A ausência de potássio na solução nutritiva provocou diminuição no teor desse elemento na parte aérea e raiz, em comparação com o tratamento completo, obtendo valores de 27,9 e $4,7 \mathrm{~g} \mathrm{~kg}^{-1}$ na parte aérea, e 20,3 e 2,8 $\mathrm{g} \mathrm{kg}^{-1}$ nas raízes (Tabela 2). Essa redução de potássio na parte aérea, no tratamento com omissão do nutriente, representou queda de $83 \%$ do teor foliar, estando abaixo da faixa adequada indicada por Ambrosano et al. (1997), de $17-30 \mathrm{~g} \mathrm{~kg}^{-1}$, e abaixo do teor foliar de 15 $\mathrm{g} \mathrm{kg}^{-1}$, considerado como adequado por Malavolta et al. (1997), o que demonstra que as plantas estavam com deficiência nutricional. Além disso, as plantas submetidas à omissão do potássio aumentaram os teores de $\mathrm{N}, \mathrm{P}, \mathrm{Ca}, \mathrm{Mg}$ e $\mathrm{S}$ na parte aérea da cultura (Tabela 2).
Com a omissão de K, pôde-se observar diminuição significativa no acúmulo de todos os macronutrientes analisados na parte aérea, raiz e planta inteira, em relação às plantas que receberam o tratamento completo devido a redução da massa seca (Tabela 3).

A ausência de potássio na solução nutritiva diminuiu o crescimento e a produção da massa seca e induziu o surgimento de sintomas visuais característicos de deficiência de potássio. As plantas de amendoim apresentaram sintomatologia de deficiência, iniciando os sintomas com clorose, seguido de escurecimento de pontos nas margens foliares, que progridem, afetando toda a folha e causando aspecto de queima necrótica, seguida da morte do tecido foliar e queda das folhas. Estes resultados estão de acordo com os observados por Rodrigues Filho et al. (1988) nas mesmas condições de experimentação.

\section{Cálcio}

Pôde-se notar que as plantas que não receberam cálcio apresentaram redução significativa na altura das plantas, no diâmetro do caule, no número de folhas, bem como na leitura do índice SPAD, em relação ao tratamento completo, resultando em diminuição da produção da massa seca da parte aérea, raízes e planta inteira do amendoim (Tabela 1). Salienta-se que o sistema radicular foi a parte da planta mais afetada pela omissão do $\mathrm{Ca}$, obtendo queda de aproximadamente $69 \%$ da massa seca das raízes em relação ao tratamento completo.

Esse fato é explicado pela função do cálcio na planta, fazendo parte das pectinas por meio dos pectatos de cálcio, sendo requerido para a alongação e a divisão mitótica celular, refletindo diretamente no crescimento radicular Prado (2008).

Observa-se que as plantas submetidas à omissão de $\mathrm{Ca}$ apresentaram menor teor do nutriente na parte aérea e raiz, sendo os teores de cálcio obtidos no tratamento completo e no tratamento com omissão do elemento, respectivamente, de 10,4 e $1,6 \mathrm{~g} \mathrm{~kg}^{-1}$ na parte aérea, e 9,3 e $3,6 \mathrm{~g} \mathrm{~kg}^{-1}$ na raiz, com efeito significativo (Tabela 2). A faixa de teor de Ca considerada adequada, segundo Ambrosano et al. (1997), é de $12-20 \mathrm{~g} \mathrm{~kg}^{-1}$, acima do teor observado no tratamento completo. Essas diferenças no teor de Ca do tratamento completo e o da literatura dão-se, possivelmente, pela distinção do material vegetal analisado, pois, no presente trabalho, consideraram-se todas as folhas da parte aérea, e da literatura, apenas o tufo apical.

O maior acúmulo de $\mathrm{Ca}$ pelas plantas ocorreu no tratamento com solução nutritiva completa, obtendo acúmulo na parte aérea, raiz e planta inteira de 157,$4 ; 19,3$ e 167,1 mg por planta, respectivamente, mas no tratamento com a omissão do nutriente, o acúmulo foi menor (96, 88 e $92 \%$ ) na parte aérea, raiz e planta inteira, correspondendo a teores de Ca acumulados de 5,5; 2,3 e 11,8 mg por planta, respectivamente (Tabela 3 ).

As plantas do tratamento com omissão de 
cálcio apresentaram sintomatologia de deficiência típica, ocorrendo redução drástica no crescimento das plantas, tanto da parte aérea como das raízes, folhas com as margens recortadas e tortas, com pontos necróticos no tecido.

Esses sintomas são semelhantes aos observados na literatura, ou seja, a deficiência de Ca leva à redução do crescimento de tecidos meristemáticos, sendo observados primeiro nas extremidades em crescimento, tecidos jovens e as folhas podem exibir deformações, especialmente das margens (Prado, 2008).

\section{Magnésio}

Quanto ao tratamento com omissão de magnésio, houve diminuição significativa da altura, diâmetro de caule, número de folhas, leitura do índice SPAD, bem como da massa seca da parte aérea e da planta inteira do amendoim (Tabela 1).

$\mathrm{O}$ tratamento completo apresentou teor de $\mathrm{Mg}$ na parte aérea e na raiz, de $6,2 \mathrm{~g} \mathrm{~kg}^{-1}$ e de $4,6 \mathrm{~g}$ $\mathrm{kg}^{-1}$, respectivamente, enquanto no tratamento com omissão deste nutriente, o teor de $\mathrm{N}$ na parte aérea e raiz foi de 0,96 e $0,7 \mathrm{~g} \mathrm{~kg}^{-1}$, respectivamente (Tabela 2).

Segundo Ambrosano et al. (1997), a faixa de teor considerada adequada nas folhas de amendoim é de $3-8 \mathrm{~g} \mathrm{~kg}^{-1}$ de $\mathrm{Mg}$, coletadas no florescimento, no tufo apical do ramo principal. Segundo Malavolta et al. (1997), a faixa de teor de Mg considerada adequada para a cultura do amendoim corresponde aos valores de teor de $3 \mathrm{~g} \mathrm{~kg}^{-1}$, constatando que as plantas submetidas ao tratamento com omissão de $\mathrm{Mg}$ estavam deficientes deste macronutriente.

Da mesma forma, ocorreu com o Mg acumulado pela parte aérea das plantas, tendo maior acúmulo do nutriente no tratamento completo $(93,7$ mg por planta), comparado ao deficiente (parte aérea $=10,8 \mathrm{mg}$ por planta) (Tabela 3 ).

Entretanto, cabe ressaltar que, apesar da diferença significativa dos teores de magnésio do tratamento completo em relação ao tratamento com omissão de $\mathrm{Mg}$, a massa seca da raiz não apresentou diferença estatística (Tabela 2); contudo, quando se avaliou o acúmulo de magnésio nas raízes, houve redução significativa de $84 \%$ nas raízes e $88 \%$ de $\mathrm{Mg}$ na planta inteira (Tabela 3 ).

Houve, ainda, um incremento no teor de $\mathrm{N}$, $P, K$ e Ca na parte aérea e raiz, em função da omissão do Mg (Tabela 2). Além disso, a omissão do Mg na solução nutritiva afetou outros nutrientes, diminuindo o acúmulo dos macronutrientes na planta inteira, exceto o $\mathrm{P}$ (Tabela 3). Assim, percebe-se que o efeito da omissão do $\mathrm{Mg}$ no incremento do teor de N, K e Ca na parte aérea (Tabela 2), provavelmente, ocorreu em função da concentração do nutriente nos tecidos, pois não houve reflexo no acúmulo destes nas plantas (Tabela 3 ).

O tratamento com omissão do magnésio resultou, ainda, no surgimento de sintomas visuais característicos de desordem nutricional de magnésio nas plantas de amendoim, com aparecimento de clorose entre as nervuras das folhas mais velhas.
Tal fato acontece, devido a conhecida mobilidade do $\mathrm{Mg}$, sendo mobilizado das folhas mais velhas para os tecidos mais jovens da planta.

Segundo Taiz \& Zeiger (2004), plantas deficientes em Mg translocam menor quantidade de carboidratos da parte aérea para a raiz, reduzindo o crescimento das raízes, fato não observado neste experimento, devido à semelhança da massa seca das raízes do tratamento com omissão de magnésio, em relação ao tratamento completo.

\section{Enxofre}

Notou-se que a omissão desse macronutriente afetou a altura, o diâmetro do caule e a leitura do índice SPAD, quando comparado ao tratamento completo (Tabela 1). Portanto, a cultura do amendoim apresentou maior tolerância à deficiência de enxofre, pois a omissão desse nutriente provocou menor prejuízo nas variáveis biométricas indicativas de desenvolvimento das plantas, quando comparado à omissão dos outros macronutrientes, sem reduzir a produção da massa seca das plantas (Tabela 1).

Entretanto, as plantas submetidas à omissão de S apresentaram redução significativa no teor do nutriente. O tratamento completo apresentou teor de $S$ na parte aérea de $1,2 \mathrm{~g} \mathrm{~kg}^{-1}$, enquanto no tratamento com omissão deste nutriente, o teor de $\mathrm{S}$ na parte aérea foi de $0,7 \mathrm{~g} \mathrm{~kg}^{-1}$ (Tabela 2). A faixa de teor de $S$ na cultura do amendoim, considerada adequada varia de 2 a $3,5 \mathrm{~g} \mathrm{~kg}^{-1}$, segundo Ambrosano et al. (1997). Apesar de o teor de S encontrado no tratamento completo estar abaixo da faixa adequada, considerada por estes autores, não foi observado sintomatologia de deficiência nutricional no tratamento completo.

Quanto à absorção do enxofre pelas plantas, o tratamento completo obteve o maior acúmulo com teor de $S$ na parte aérea e na planta inteira, de 18,9 e $26,3 \mathrm{mg}$ planta $^{-1}$, respectivamente, comparado ao tratamento com omissão do elemento, com teor na parte aérea e na planta inteira de 10,2 e $16,9 \mathrm{mg}$ de $\mathrm{S}$ por planta, respectivamente (Tabela $3)$.

Outro fato interessante a ser ressaltado é que a omissão de $S$ afetou outros nutrientes, com aumento significativo no teor de N, K e Ca na parte aérea, comparado ao tratamento completo (Tabela 2).

Em decorrência da omissão de S, observaram-se, nas plantas de amendoim, folhas velhas amareladas, cuja sintomatologia foi observada na fase final do experimento.

É válido ressaltar que a deficiência de enxofre é bastante semelhante à deficiência de nitrogênio, embora o amendoim não tenha apresentado a clorose uniforme nas folhas mais velhas.

Por fim, observou-se, no tratamento completo, a seguinte ordem de extração de nutrientes da parte aérea $(\mathrm{K}>\mathrm{N}>\mathrm{Ca}>\mathrm{Mg}>\mathrm{P}>\mathrm{S})$; raízes $(\mathrm{N}>\mathrm{K}>\mathrm{P}>\mathrm{Ca}>\mathrm{Mg}>\mathrm{S})$, e da planta inteira $(\mathrm{K}>\mathrm{N}>\mathrm{Ca}>\mathrm{Mg}>\mathrm{P}>\mathrm{S})$ (Tabela 3$)$. Enquanto Feitosa 
CORREIA, M.A.R. et al. Avaliação da desordem nutricional...

et al. (1993) observaram a seguinte ordem de extração de nutrientes em quatro cultivares de amendoim: $\mathrm{N}>\mathrm{K}>\mathrm{Ca}>\mathrm{Mg}>\mathrm{P}>\mathrm{S}$. Essas diferenças ocorrem devido aos sistemas de cultivos e genótipos distintos. Os resultados deste trabalho indicam que o $\mathrm{Ke}$ o $\mathrm{N}$ foram os nutrientes mais requeridos pelo amendoim cv. Runner IAC 886 sob sistema de cultivo hidropônico.

\section{CONCLUSÃO}

Os tratamentos com as omissões individuais de $\mathrm{K}, \mathrm{Ca}, \mathrm{N}, \mathrm{P}$ e $\mathrm{Mg}$ foram os que mais limitaram a produção de massa seca do amendoim. Os teores de nutrientes observados nas plantas de amendoim do tratamento completo e da omissão, na parte aérea, foram, respectivamente: $\mathrm{N}=19,0 \mathrm{e}$ 12,$2 ; \mathrm{P}=4,7$ e 1,$1 ; \mathrm{K}=27,9$ e 4,$7 ; \mathrm{Ca}=10,4$ e 1,6; $\mathrm{Mg}=6,2$ e 0,$96 ; \mathrm{S}=1,2$ e $0,7 \mathrm{~g} \mathrm{~kg}^{-1}$.

\section{REFERÊNCIAS}

1. AMBROSANO, J.E.; TANAKA, R.T.; MASCARENHAS, H.A.A.; RAIJ, B. van; QUAGGIO, J.A.; CANTARELLA, H Leguminosas e oleaginosas. In: RAIJ, B. van; CANTARELLA, H.; QUAGGIO, J.A.; FURLANI, A.M.C. (Ed.). Recomendações de adubação e calagem para o Estado de São Paulo. Campinas: Instituto Agronômico e Fundação IAC, 1997. p. 189-203.

2. BATAGLIA, O.C.; FURLANI, A.M.C.; TEIXEIRA, J.P.F.; FURLANI, P.R.; GALLO, J.R. Métodos de análise química de plantas. Campinas: Instituto Agronômico, 1983. 48p. (Circular 78).

3. BARBOSA, J. C.; MALDONADO JÚNIOR, W. Software AgroEstat - Sistema de análises estatísticas de ensaios agronômicos. Universidade Estadual Paulista, Faculdade de Ciências Agrárias e Veterinárias, Câmpus de Jaboticabal, Brasil, 2009.

4. CAIRES, E.F.; ROSOLEM, C.A. Efeitos da calagem, cobalto e molibdênio sobre a concentração de clorofila nas foIhas de amendoim. Revista Brasileira de Ciência do Solo, v.23, n.1, p.79-84, 1999.

5. COELHO, F. A. S.; TELLA, R. Absorção de nutrientes por plantas de amendoim na cultura do outono. Bragantia, v.26, n.18, p.335-352, 1967.

6. CRUSCIOL, C.A.C. \& SORATTO, R.P. Nutrição e produtividade do amendoim em sucessão ao cultivo de plantas de cobertura no sistema plantio direto. Pesquisa Agropecuária Brasileira, v.42, n.11, p.1553-1560, 2007.

7. FEITOSA, C.T.; NOGUEIRA, S.S.S.; GERIN, M.A.N.; RODRIGUES FILHO, F.S.O. Avaliação do crescimento e da utilização de nutrientes pelo amendoim. Scientia Agricola, v.50, n.3, p.427-437, 1993.

8. FREIRE, R. M. M.; NARAIN, N; SANTOS, R. C. Aspectos nutricionais de amendoim e seus derivados. In: SANTOS R. C. (Ed.). O agronegócio do amendoim no Brasil. Campina Grande: Embrapa Algodão, 2005. p. 389-420.

9. HOAGLAND, D.R.; ARNON, D. I. The water culture method for growing plants without soils. California: Agricultural Experimental Station, 1950. $347 \mathrm{p}$.

10. LOMBARDI, A.C. Subsídios para elaboração de um plano visando à produção de alimentos nas regiões canavieiras. Brasil Açucareiro, v.103, n.2-3, p.9-23, 1985.

11. MALAVOLTA, E.; VITTI, G.C.; OLIVEIRA, S. Avaliação do estado nutricional das plantas. 2ed. Piracicaba: POTAFÓS, 1997. 319p.

12. MENGEL, K.; KIRKBY, E.A. Principles of plant nutrition. Bem: Intern. Postash Institute, 1987. 687p.

13. PRADO, R.M. Nutrição de Plantas. São Paulo: Unesp, 2008. 407 p.

14. RODRIGUES FILHO, F.S.O.; FEITOSA, C.T.; GERIN, M.A.N. Omissão de macronutrientes em plantas de amendoim. Bragantia, v.47, n.2, p.305-312, 1988.

15. TAIZ, L.; ZEIGER, E. Fisiologia vegetal. 3.ed. Porto Alegre: Artmed, 2004. 719p.

Recebido em 23/11/2010

Aceito em 05/04/2012 